Check for updates

Tenterden, Kent

Cite this as: BMJ 2021;373:n1315 http://dx.doi.org/10.1136/bmj.n1315 Published: 21 May 2021

\title{
Covid-19: UK cases of variant from India rise by $160 \%$ in a week
}

\section{Jacqui Wise}

Failures in the government's test and trace system may have contributed to the spread of the B.1.617.2 variant in the UK, cases of which have risen by more than $160 \%$ in the past week.

Cases of the B.1.617.2 variant, first detected in India, rose from 1313 to 3424 in the week to 19 May, show data from Public Health England. ${ }^{1}$ The variant is still predominantly affecting the north west of England and London, but there are clusters across the country.

A further variant, known as VUI-21MAY-01 or AV.1, has been designated by Public Health England as a "variant under investigation." There have been 49 cases of this variant across the country, mainly concentrated in Yorkshire and the Humber. It has been detected in the UK, Greece, and Chad, though its origin is unclear. ${ }^{2}$

Public Health England said that there was currently no evidence that covid-19 vaccines will be less effective in protecting people against either B.1.617.2 or AV.1.

A software error meant that eight local authorities did not have access to the full data on positive test results in their areas between 17 April and 17 May. These included Blackburn with Darwen, which has experienced a sharp rise in cases of the B.1.617.2 variant. The other local authorities were Blackpool, York, Southend-on-Sea, Thurrock, Bristol, North Somerset and Bath, and North East Somerset.

The $\mathrm{BBC}$ reported that the IT glitch meant that 734 positive tests were not reported to local authorities, meaning that contacts could not be traced locally. ${ }^{3}$ The Department of Health and Social Care told Blackburn with Darwen Council that there were 164 cases it had been unaware of. The people affected were subsequently traced, but another 130 infected people had passed the 10-day isolation period and could not be followed up.

The government added India to the red list of countries, from which travellers must quarantine in a hotel on return, on 23 April, almost a week after the problems with NHS Test and Trace started.

A spokesperson for the Department of Health and Social Care said the technical error was caused by a glitch in an IT system upgrade that had now been fully resolved. "Due to a software issue, there was a delay in tracing contacts of a number of cases. This only affected a handful of local authorities, and the issue was resolved as quickly as possible," the spokesperson said.

Jonathan Ashworth, Labour's shadow health secretary, said, "It beggars belief that yet again local health experts on ground have been left in the dark for two weeks when we know acting with speed is vital to containing an outbreak." He added, "Ministers need to explain what's gone wrong and provide local health directors with all the resources they need to push infections down."

Public Health England said that it was working closely with borough councils with clusters of the B.1.617.2 variant. In Bolton more than 33 ooo test kits have been given out as part of the surge testing programme. In Blackburn with Darwen and Sefton mobile and drive-through test centres have been set up, new vaccination centres have opened, and additional supply of first doses secured. Wastewater monitoring has been increased in affected areas to help identify early warning signals of where variants may be present.

The government's Scientific Advisory Group for Emergencies has said it was a realistic possibility that the B.1.617.2 variant is as much as 50\% more transmissible than the B.1.1.7 variant. ${ }^{4}$

Blackburn with Darwen has seen the second biggest rise in reported SARS-CoV-2 infections in the country, from 104.9 cases per 100 ooo people in the seven days to 9 May to 159.7 per 100 ooo up to 16 May. Bolton continues to have the highest rate: up from 189.2 to 341.5 cases per 100 ooo.

Writing in the Lancashire Telegraph, Dominic Harrison, Blackburn with Darwen Council's public health director, said, “A very high percentage of our cases are of B1.617.2. Bolton has similarly rising covid rates and variant cases. In terms of transmission and spread, Blackburn with Darwen may be a week to ten days behind Bolton."

He said seeding of cases of B.1.617.2 occurred as travellers returned during April. "The seeding is not the fault of the travellers. The root causes are related to systemic failures and operational weaknesses in the national measures we have in place to control the risks of international travel, including red listing and the subsequent arrangements for quarantine, self-isolation, and test and trace."5

Public Health England. Variants: distribution of cases data May 2021.20 May 2021. https://www.gov.uk/government/publications/covid-19-variants genomically-confirmed-case-numbers/variants-distribution-of-cases-data.

2 COG-UK. Variants of concern (VOC) and under investigation (VUI) detected in the UK data. http://sars2.cvr.gla.ac.uk/cog-uk.

3 Ash S, Kuenssberg L. Covid: Test and Trace failure helped Indian variant spread, report says. BBC News. 20 May 2021. https://www.bbc.co.uk/news/uk-politics-57186059.

4 Scientific Advisory Group for Emerg encies. SAGE 89 minutes: Coronavirus (COVID-19) response, 13 May 2021. https://www.gov.uk/government/publications/sage-89-minutes-coronavirus-covid-19-response-13-may-2021.

5 Harrison D. Column: How cases of the "Indian variant" of Covid grew in Blackburn with Darwen. Lancashire Telegraph. 21 May 2021.

https://www.lancashiretelegraph.co.uk/news/19317046.blackburn-darwenhealth-boss-follow-rules-fight-indian-variant.

This article is made freely available for use in accordance with BMJ's website terms and conditions for the duration of the covid-19 pandemic or until otherwise determined by BMJ. You may use, download and print the article for any lawful, 
non-commercial purpose (including text and data mining) provided that all copyright notices and trade marks are retained. 